\title{
Ferrite recrystallization and austenite formation at the early stage of annealing in cold-rolled low-carbon steels
}

\author{
Toshio Ogawa
}

\begin{abstract}
Background: High strength low carbon steels used in the automobile industry are often annealed at the intercritical temperature, and recrystallization of ferrite and formation of austenite can occur at the same time during the intercritical annealing. However, detailed studies on the competition between recrystallization of ferrite and formation of austenite at the early stage of annealing have not been carried. Therefore, ferrite recrystallization and austenite formation in cold-rolled low carbon steels at an early stage of annealing have been observed.
\end{abstract}

Methods: The chemical composition of the steel (in mass \%) was $0.1 \mathrm{C}-2.0 \mathrm{Mn}$. After hot and cold rolling, the specimens were heated from room temperature to 1003, 1013 and $1023 \mathrm{~K}$ at a rate of $30 \mathrm{~K} \mathrm{~s}^{-1}$, and then gas-quenched to room temperature at a rate of $50 \mathrm{~K} \mathrm{~s}^{-1}$. We observed the microstructure of the annealed specimens.

Results: Fractions of recrystallized ferrite and austenite gradually increased with increasing annealing temperature, whereas the fraction of non-recrystallized ferrite gradually decreased with increasing annealing temperature. A large portion of austenite was formed at the grain boundaries of recrystallized ferrite and at the interface between recrystallized and non-recrystallized ferrite grains, whereas formation of austenite was scarcely confirmed at subgrain boundaries inside non-recrystallized ferrite grains. The grain size of the recrystallized ferrite and the subgrains formed in the non-recrystallized ferrite hardly changed during the annealing.

Conclusions: Ferrite recrystallization was able to proceed during intercritical annealing when the austenite fraction was less than at least 10\%. A large portion of austenite was formed at the grain boundaries of the recrystallized ferrite and the interface between the recrystallized ferrite and non-recrystallized ferrite at an early stage of annealing at the intercritical temperature.

Keywords: Recovery; Recrystallization; Austenite formation; Low-carbon steel

\section{Background}

Interstitial free (IF) steels are generally annealed in the ferrite $(\alpha)$ single region (Hashimoto et al. 1998; Mukunthan and Hawbolt 1996; Nishitani et al. 2011; Takechi 1994; Ye et al. 2002). In contrast, high-strength low-carbon steels used in the automobile industry are often annealed at the intercritical temperature (Garcia et al. 2005; Hayami et al. 1979; Goodman 1984; Takayama et al. 1982; Toji et al. 2011). During the intercritical annealing, recrystallization of $\alpha$ and formation of austenite $(\gamma)$ can occur at the same

Correspondence: ogawa@m.kisarazu.ac.jp

Department of Mechanical Engineering, National Institute of Technology,

Kisarazu College, 2-11-1 Kiyomidai-higashi, Kisarazu-shi, Chiba 292-0041, Japan time in low-carbon steels. Therefore, the microstructural evolution during intercritical annealing in low-carbon steels is sometimes complicated compared to IF steels.

In our previous studies, when low-carbon steels were heated above the $\mathrm{Ac}_{1}$ temperature before the completion of $\alpha$ recrystallization, remarkable retardation of $\alpha$ recrystallization was observed when the $\gamma$ fraction was above 30 \% (Maruyama et al. 2007; Ogawa et al. 2010). On the other hand, Yang et al. investigated the role of $\gamma$ on the recrystallization of $\alpha$ during intercritical annealing in plain low-carbon steel, and concluded that the inhibition effect of $\gamma$ is small, at least under the condition where the $\gamma$ fraction is approximately $10 \%$ (Yang et al. 1984). Therefore, it appears that the effect of the $\gamma$ fraction 
on recrystallization of $\alpha$ is an important point for microstructural evolution during intercritical annealing. However, detailed studies on the competition between recrystallization of $\alpha$ and formation of $\gamma$ during intercritical annealing have not been carried out when the $\gamma$ fraction is less than $10 \%$. From the viewpoint of controlling the microstructure during intercritical annealing in industrial manufacturing, the mechanism of progress of $\alpha$ recrystallization when the $\gamma$ fraction is less than $10 \%$ needs to be clarified.

For nucleation sites of $\gamma$, Goodman et al. demonstrated that martensite was observed at high-angle grain boundaries, such as non-recrystallized $\alpha$ grain boundaries, when the volume fraction of the martensite was approximately 15 \% (Goodman 1984). In addition, it has been reported that the formation of martensite is confirmed not only at high-angle grain boundaries but also inside non-recrystallized $\alpha$ grains when the volume fraction of the martensite is approximately $50 \%$ (Carozzo and Jacques 2007). In these studies, the positions of the martensite correspond to those of the $\gamma$ phase during intercritical annealing. Hence, it is likely that the $\gamma$ fraction is also important for the nucleation sites of $\gamma$, but this has not been explored or discussed sufficiently. The effect of the $\gamma$ fraction on the nucleation site of $\gamma$ needs to be investigated since the distribution of $\gamma$ can affect the formability of lowcarbon steels (Nonaka et al. 2007).

We mainly examined the recrystallization of $\alpha$ and the formation of $\gamma$ during intercritical annealing when the $\gamma$ fraction was above $30 \%$. However, as mentioned above, the number of detailed studies on the recrystallization of $\alpha$ and formation of $\gamma$ during intercritical annealing when the $\gamma$ fraction is less than $10 \%$ is limited. Therefore, basic data for this needs to be accumulated, and this may play an important role in determining the annealing conditions of low-carbon steels in industrial manufacturing. The purpose of the present study was to investigate the recrystallization of $\alpha$ and formation of $\gamma$ at the early stage of annealing in cold-rolled low-carbon steels.

\section{Methods}

The chemical composition of the steel (in mass \%) was $0.1 \mathrm{C}-2.0 \mathrm{Mn}$. The vacuum-melted ingot was hot rolled in the austenite region to a thickness of $3 \mathrm{~mm}$ and subsequently water-cooled to $673 \mathrm{~K}$ followed by furnace cooling to room temperature. The microstructure after hot rolling was bainite. The hot-rolled sheet was cold rolled to a thickness of $1 \mathrm{~mm}$ (reduction: $67 \%$ ). Optical micrographs of the hot-rolled and cold-rolled sheets were included in our previous article (Ogawa et al. 2010). After the cold rolling, the specimens were heated from room temperature to 1003,1013 , and $1023 \mathrm{~K}$ at a rate of $30 \mathrm{~K} \mathrm{~s}^{-1}$, and then gas-quenched to room temperature at a rate of $50 \mathrm{~K} \mathrm{~s}^{-1}$ using a heat treatment simulator.

In these steels, the $\gamma$ phase which forms during intercritical annealing was transformed to martensite $\left(\alpha^{\prime}\right)$ or bainite $\left(\alpha_{B}\right)$ during cooling. Phase transformation behavior during heating from room temperature to $1173 \mathrm{~K}$ was quantified by measuring thermal expansion using a dilatometer. The microstructure of the annealed specimens was observed by means of optical microscopy and transmission electron microscopy (TEM).

\section{Results}

Figure $1 \mathrm{a}-\mathrm{c}$ shows the microstructures of specimens heated to 1003, 1013, and $1023 \mathrm{~K}$. Recrystallized $\alpha$ grains can be observed after heating to $1003 \mathrm{~K}$ (Fig. 1a). The black points in Fig. 1a correspond to spheroidal cementite. The area of the recrystallized $\alpha$ grains increased with increasing annealing temperature (Fig. 1b, c).

Figure 2 shows the $\alpha$-to- $\gamma$ transformation behavior of a specimen during heating. The $\mathrm{Ac}_{1}$ temperature of the specimen is approximately $1008 \mathrm{~K}$. For the estimation of the $\gamma$ fraction from the change in dilatation (Fig. 2a), the following equation was used:

$$
\mathrm{F}_{\gamma}=\frac{D_{\alpha+\gamma}-D_{\alpha}}{D_{\gamma}-D_{\alpha}} \times 100
$$

where $F_{\gamma}$ is the $\gamma$ fraction at each temperature, $D_{\gamma}$ is the dilatation obtained by the dilatometer when the specimen is heated to the austenite single region, $D_{\alpha}$ is the dilatation obtained by the dilatometer when the specimen is heated to the ferrite single region, and $D_{\alpha+\gamma}$ is the dilatation obtained by the dilatometer at each temperature above the $\mathrm{Ac}_{1}$ temperature. The parameters of $\mathrm{D}_{\gamma}, \mathrm{D}_{\alpha}$, and $\mathrm{D}_{\alpha+\gamma}$ are illustrated in Fig. 2a. Using Eq. (1), the $\gamma$ fractions that were transformed during heating to 1013 and $1023 \mathrm{~K}$ are calculated to be 5 and $10 \%$ approximately, respectively (Fig. $2 \mathrm{~b}$ ). Changes in the volume fraction of the microstructure in the specimens heated to 1003, 1013, and $1023 \mathrm{~K}$ are shown in Fig. 3. The fraction of recrystallized $\alpha$ shown in Fig. 3 was estimated by the point-count method. The fraction of nonrecrystallized $\alpha$ shown in Fig. 3 can be obtained by the following equation:

$$
F_{\mathrm{NR}}=100-\left(F_{\mathrm{R}}+F_{\gamma}\right)
$$

where $F_{\mathrm{NR}}$ is the fraction of non-recrystallized $\alpha$ and $F_{\mathrm{R}}$ is the fraction of recrystallized $\alpha$. Fractions of recrystallized $\alpha\left(\alpha_{\mathrm{R}}\right)$ and $\gamma$ gradually increased with increasing annealing temperature, whereas the fraction of nonrecrystallized $\alpha\left(\alpha_{\mathrm{NR}}\right)$ gradually decreased with increasing annealing temperature. Recrystallized fractions of 


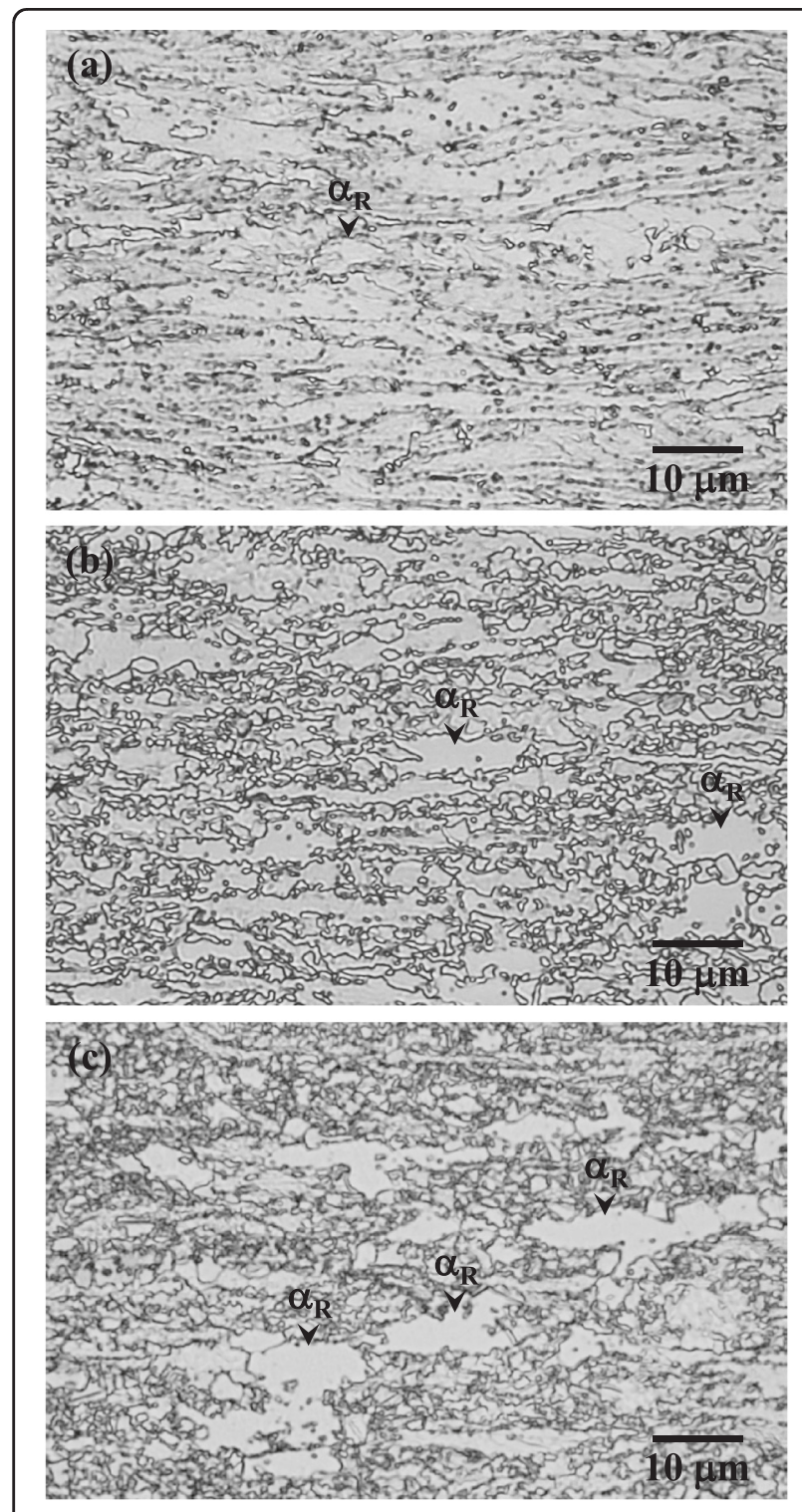

Fig. 1 Optical micrographs of a specimen heated to 1003 (a), 1013 (b), and $1023 \mathrm{~K}(\mathbf{c})$
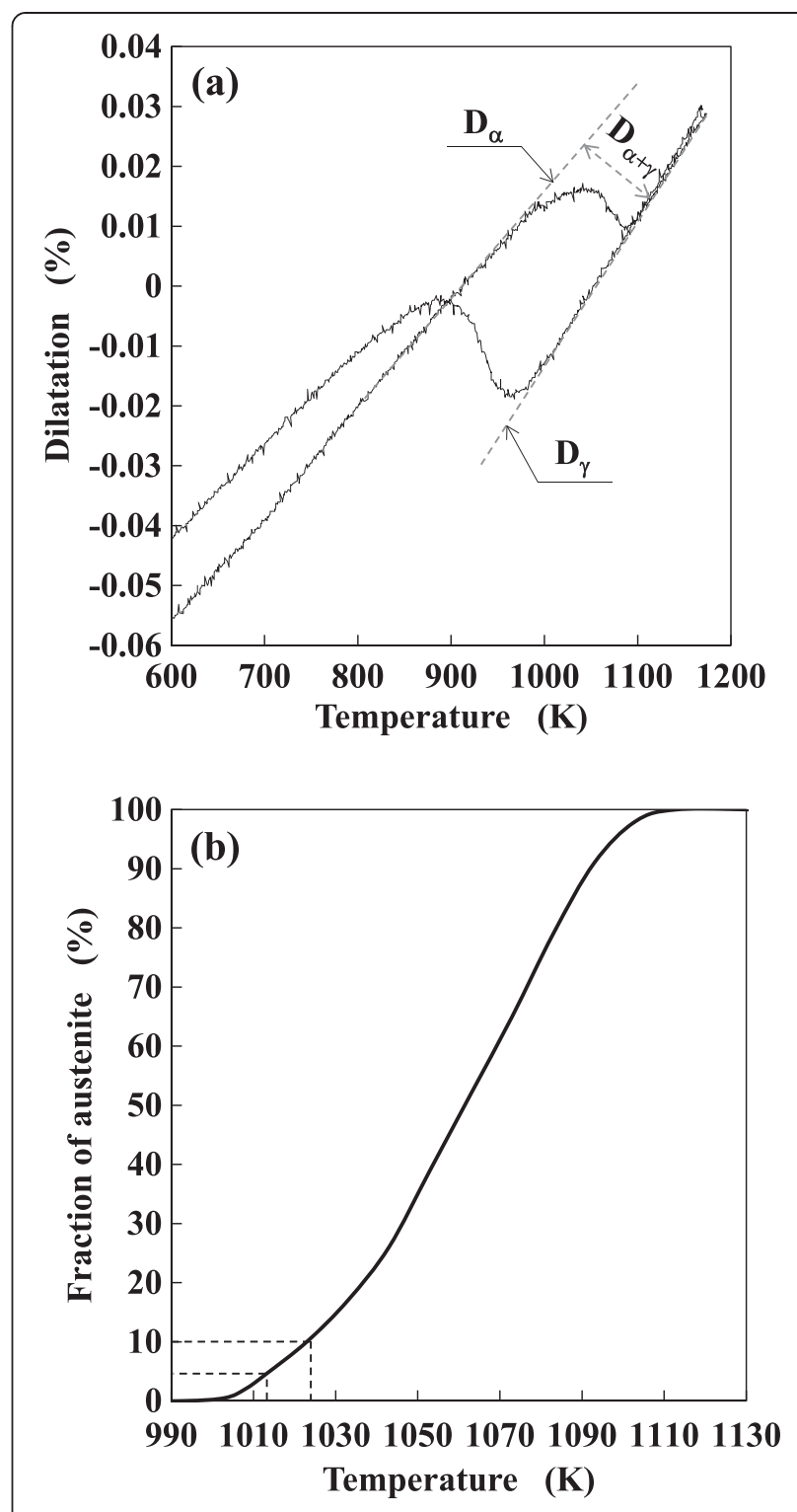

Fig. $\mathbf{2}$ Changes in a dilatation and $\mathbf{b}$ fraction of austenite in microstructures of the specimens during heating the specimens heated to 1003,1013 , and $1023 \mathrm{~K}$ are approximately 20,35 , and $50 \%$, respectively.

The microstructures in a specimen heated to $1003 \mathrm{~K}$ are shown in Fig. $4 \mathrm{a}-\mathrm{c}$. Since the $\mathrm{Ac}_{1}$ temperature is approximately $1008 \mathrm{~K}$, the temperature at which the specimen was annealed is in the $\alpha$ single region. The microstructure shown in Fig. 4a consists of $\alpha_{\mathrm{R}}$ and $\alpha_{\mathrm{NR}}$. Here, we assume that the grains with diameters larger than $3 \mu \mathrm{m}$ correspond to recrystallized $\alpha$ grains. Cementite particles are observed both in the $\alpha_{\mathrm{R}}$ (Fig. 4b) and $\alpha_{\mathrm{NR}}$ (Fig. 4c), and subgrains (SG) are formed in the $\alpha_{\mathrm{NR}}$ (Fig. 4c).
Figures 5 and 6 show microstructures of specimens heated to 1013 and $1023 \mathrm{~K}$. Since the dislocation density in $\alpha^{\prime}$ is extremely high compared to that in $\alpha_{\mathrm{R}}$ and $\alpha_{\mathrm{NR}}$, we determined that the grains with higher dislocation densities and without precipitation of carbides correspond to $\alpha^{\prime}$ in Figs. 5 and 6. The microstructures shown in Figs. $5 \mathrm{a}$ and $6 \mathrm{a}$ consist of $\alpha_{\mathrm{R}}, \alpha_{\mathrm{NR}}$, and transformation products from $\gamma$ (i.e., $\alpha^{\prime}$ ), and cementite particles are hardly observed in $\alpha_{\mathrm{R}}$ and $\alpha_{\mathrm{NR}}$. A large portion of $\gamma$ is formed at the grain boundaries of $\alpha_{\mathrm{R}}$ and at the interface between $\alpha_{\mathrm{R}}$ and $\alpha_{\mathrm{NR}}$, whereas formation of $\gamma$ is scarcely confirmed at subgrain boundaries inside $\alpha_{\mathrm{NR}}$ (Figs. 5b and 6b). 


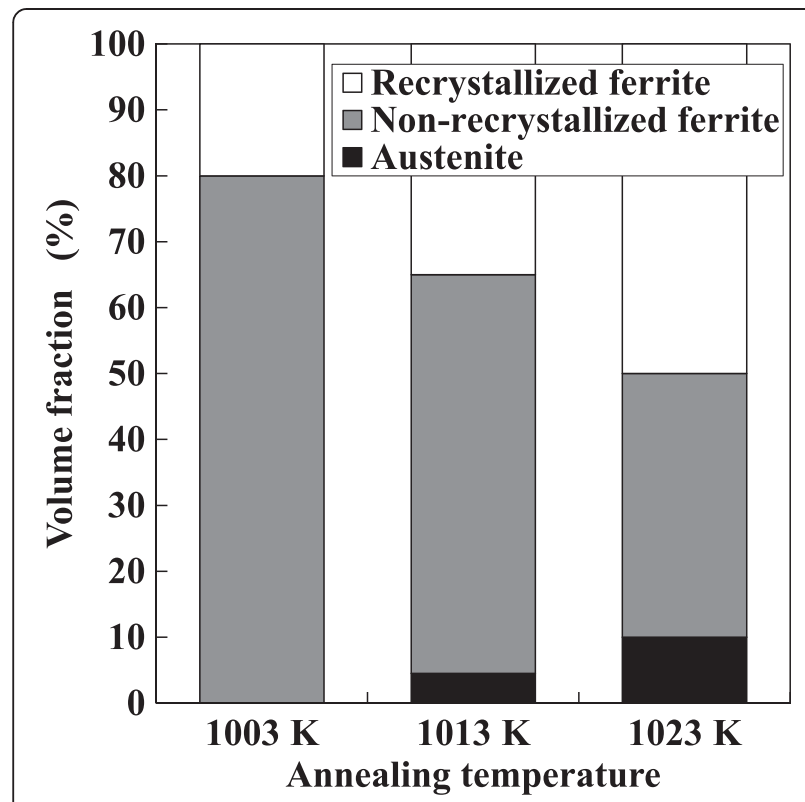

Fig. 3 Changes in fractions of recrystallized ferrite, non-recrystallized ferrite, and austenite in microstructures of the specimens during heating

Figure 7 shows changes in the grain size of $\alpha_{\mathrm{R}}$ and the subgrain size in $\alpha_{\mathrm{NR}}$ during heating to $1023 \mathrm{~K}$. The grain size of $\alpha_{\mathrm{R}}$ hardly changed during heating to $1023 \mathrm{~K}$ and was approximately $6.0 \mu \mathrm{m}$. Subgrain growth was scarcely observed during heating to $1023 \mathrm{~K}$ and the size of subgrains formed in $\alpha_{\mathrm{NR}}$ is approximately $0.75 \mu \mathrm{m}$.

\section{Discussion}

The microstructural evolution during heating to $1023 \mathrm{~K}$ showed some characteristic points regarding recrystallization of $\alpha$ and the formation of $\gamma$ as compared to our previous study (Ogawa et al. 2010). The mechanism of microstructural evolution in the present study is discussed involving both recrystallization of $\alpha$ and the formation of $\gamma$.

\section{Ferrite recrystallization}

As shown in Fig. 3, the fraction of $\alpha_{\mathrm{R}}$ gradually increased with the annealing temperature. This suggests that recrystallization of $\alpha$ can proceed during intercritical annealing when the $\gamma$ fraction is less than $10 \%$. The results of this study are in agreement with previous studies (Ogawa et al. 2010; Yang et al. 1984). On the other hand, we demonstrated that remarkable retardation of $\alpha$ recrystallization was observed during intercritical annealing when the $\gamma$ fraction was above $30 \%$ (Maruyama et al. 2007; Ogawa et al. 2010). Thus, it is likely that the progress of $\alpha$ recrystallization depends on the $\gamma$ fraction during intercritical annealing.
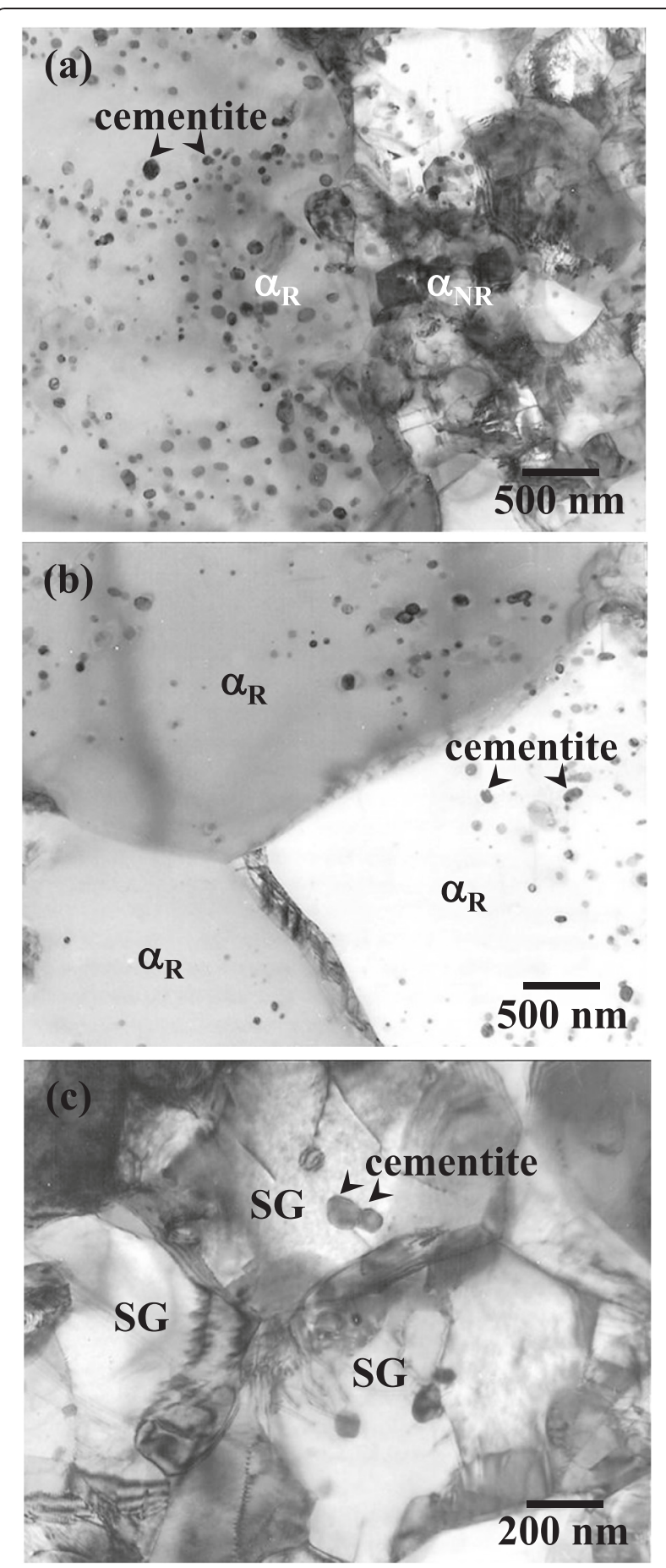

Fig. 4 TEM images of a recrystallized and non-recrystallized ferrite grains, $\mathbf{b}$ recrystallized ferrite grains, and $\mathbf{c}$ non-recrystallized ferrite grains in the microstructure of a specimen heated to $1003 \mathrm{~K}$

In the present study, as shown in Fig. 7, it is important to note that the grain size of $\alpha_{\mathrm{R}}$ hardly changed during heating from 1003 to $1023 \mathrm{~K}$, although the fraction of $\alpha_{\mathrm{R}}$ gradually increased with the annealing temperature 

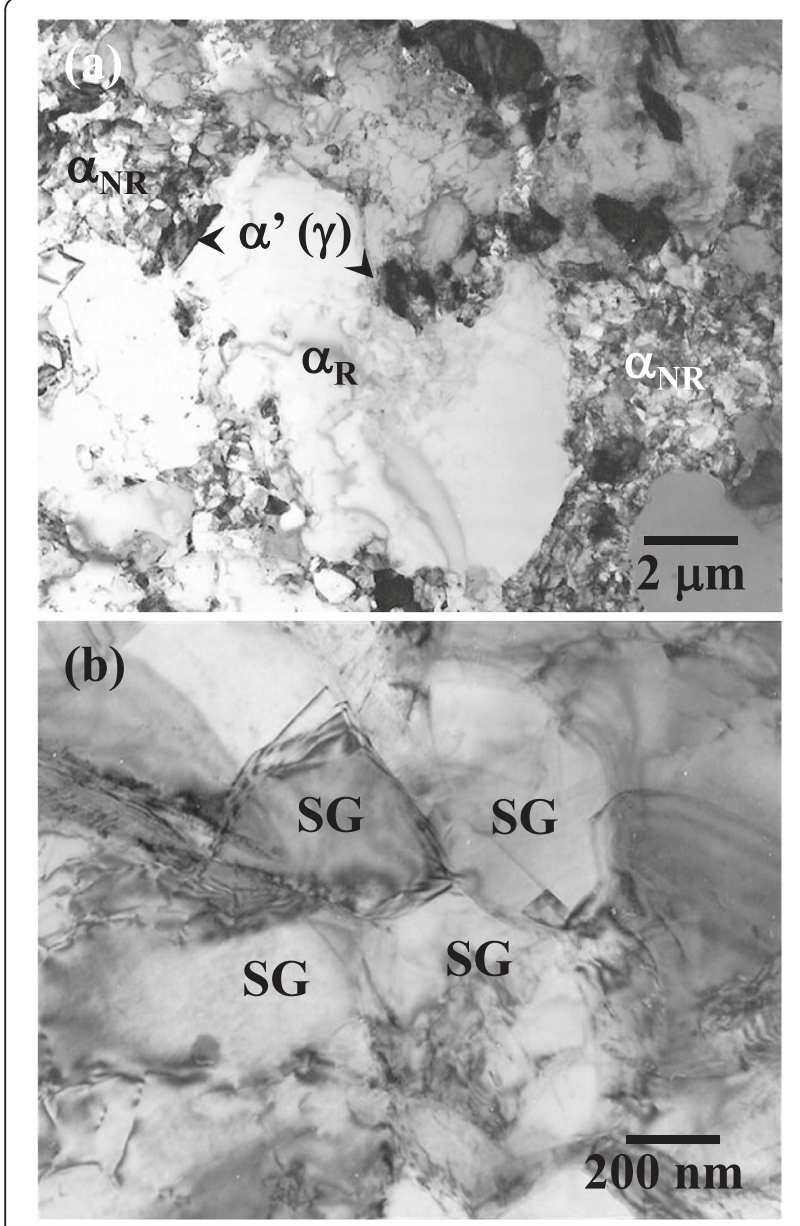

Fig. 5 TEM images of a recrystallized and non-recrystallized ferrite grains and $\mathbf{b}$ non-recrystallized ferrite grains in the microstructure of a specimen heated to $1013 \mathrm{~K}$

(Fig. 3). In addition, a large portion of $\gamma$ was formed at high-angle grain boundaries such as the grain boundaries of $\alpha_{\mathrm{R}}$ and the interface between $\alpha_{\mathrm{R}}$ and $\alpha_{\mathrm{NR}}$. For lowcarbon steels, the formation of $\gamma$ at high-angle grain boundaries during intercritical annealing has also been reported by several authors (Goodman 1984; Maruyama et al. 2007; Ogawa et al. 2010; Yang et al. 1984). For discussing the grain growth mechanism, the following type of equation (Takayama et al. 1982) is often used:

$$
r^{n}-r_{0}^{n}=\mathrm{kt}
$$

where $r$ is the average radius of the grains, $r_{0}$ is the initial radius, and $k$ is a rate constant. The value $n$ has been reported to vary with the controlling mechanism of the grain growth. For grain growth of the dual phase, the value of $k$ in Eq. (3) has been estimated to be $2.4 \times$ $10^{-13} \mathrm{~mm}^{3} \mathrm{~s}^{-1}$ (Ogawa et al. 2010). On the other hand, for grain growth of the $\alpha$ single phase, the value of $k$ in Eq. (3) has been estimated to be $1.6 \times 10^{-5} \mathrm{~mm}^{2} \mathrm{~s}^{-1}$
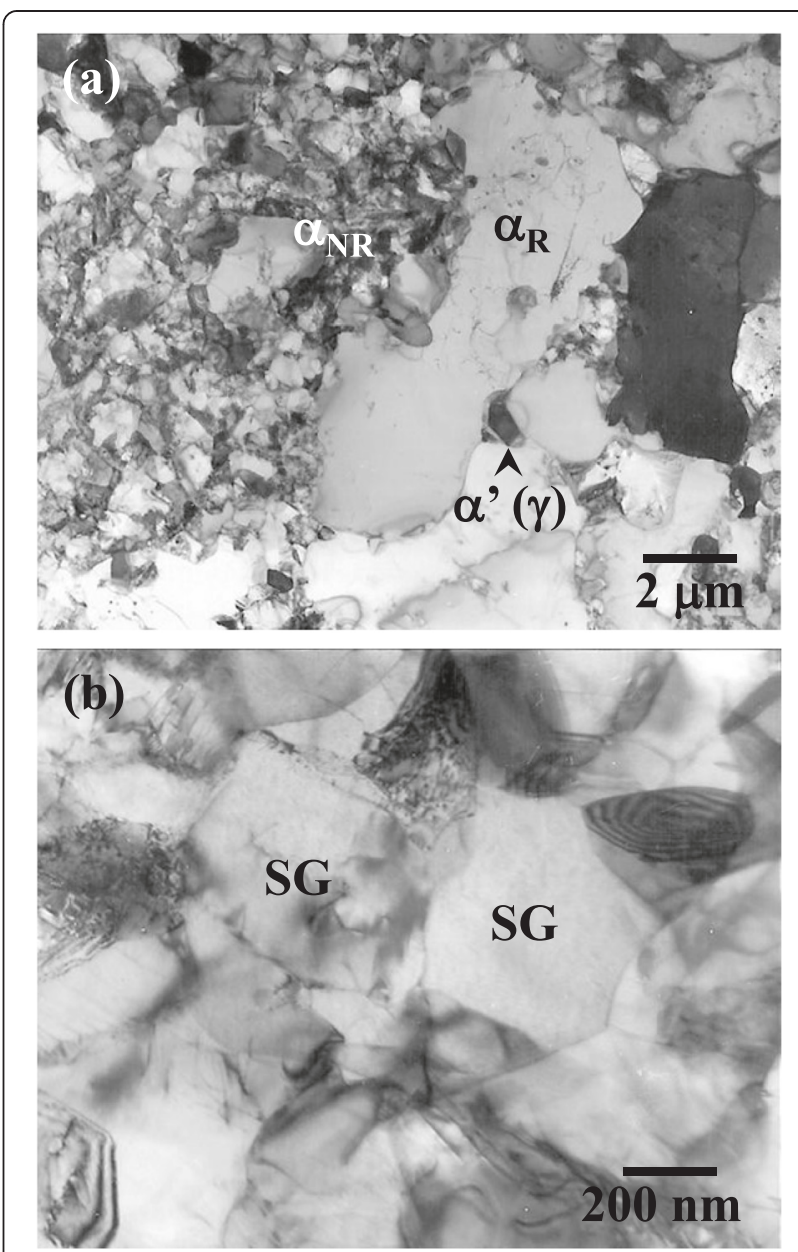

Fig. 6 TEM images of a recrystallized and non-recrystallized ferrite grains and $\mathbf{b}$ non-recrystallized ferrite grains in the microstructure of a specimen heated to $1023 \mathrm{~K}$

(Takayama et al. 1982). For grain growth of the dual phase and the single phase, the value of $n$ in Eq. (3) is 3 and 2, respectively (Nishizawa 1984). In addition, as shown in Fig. 7, $r_{0}$ (radius of the recrystallized $\alpha$ grains at $1003 \mathrm{~K}$ ) in Eq. (3) is approximately $3.1 \mu \mathrm{m}$. Substituting these values of $k, n$, and $r_{0}$ into Eq. (3), the radius of recrystallized $\alpha$ grains in the dual phase and the $\alpha$ single phase at $1023 \mathrm{~K}$ are calculated to be approximately 3.1 and $4.5 \mu \mathrm{m}$, respectively. Therefore, the mechanism of the grain growth of $\alpha_{\mathrm{R}}$ in this study can be explained by the kinetics of grain growth of the dual phase.

The mechanisms of recrystallization can be distinguished into discontinuous and continuous recrystallization. Discontinuous recrystallization is manifested by recrystallized grains appearing in the deformed matrix and consuming the matrix, and finally the entire region is converted to recrystallized grains (Humphreys 2004). On the other hand, continuous recrystallization represents cells or subgrains formed in the deformed matrix changing to recrystallized grains (Humphreys 1997). Hence, 


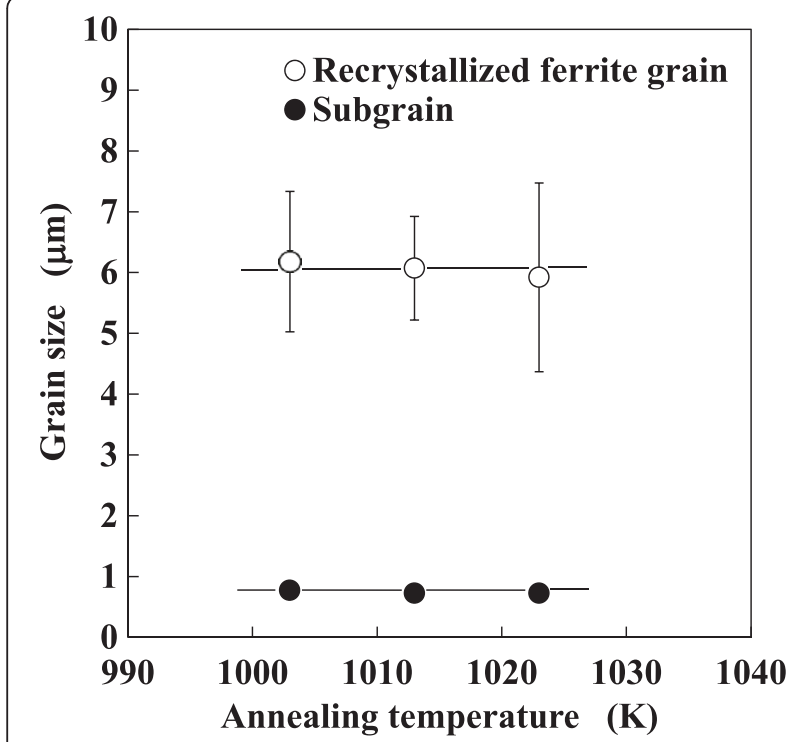

Fig. 7 Changes in the diameters of recrystallized ferrite grains and subgrains in non-recrystallized ferrite grains as functions of the annealing temperature

progress of $\alpha$ recrystallization at the early stage of annealing at the intercritical temperature in this study probably originates in continuous recrystallization since the grain size of $\alpha_{\mathrm{R}}$ hardly changed during heating from 1003 to $1023 \mathrm{~K}$.

\section{Austenite formation}

The mechanisms of $\gamma$ formation in low-carbon steels have been proposed by several authors (Hillert et al. 1971; Huang et al. 2004; Jeong and Kim 1985; Speich and Szirmae 1969; Speich et al. 1981). In many cases, it has been reported that cementite particles and/or pearlite colonies are the likely nucleation sites of $\gamma$. In the present study, however, as shown in Fig. 4, after heating to $1003 \mathrm{~K}$, the cementite particles were still homogeneously distributed and were observed both in $\alpha_{\mathrm{R}}$ and $\alpha_{\mathrm{NR}}$. Furthermore, as shown in Figs. 5 and 6, a large portion of $\gamma$ was formed at the grain boundaries of $\alpha_{\mathrm{R}}$ and the interface between $\alpha_{\mathrm{R}}$ and $\alpha_{\mathrm{NR}}$, and the transformation products from $\gamma$ were hardly observed inside $\alpha_{\mathrm{R}}$ and $\alpha_{\mathrm{NR}}$. Thus, it appears that cementite particles are not necessarily the nucleation sites for $\gamma$ in this study.

Hillert et al. suggested that solute $C$ generated by the dissolution of cementite diffused to the grain boundaries, thereby causing the formation of $\gamma$ at the grain boundaries (Hillert et al. 1971). Hence, it is likely that the mechanism of $\gamma$ formation in this study is that solute $\mathrm{C}$ generated by the dissolution diffused to the grain boundaries thereby causing the formation of $\gamma$ at the grain boundaries of $\alpha_{\mathrm{R}}$ and the interface between $\alpha_{\mathrm{R}}$ and $\alpha_{\mathrm{NR}}$ at the early stage of annealing. Here, it should be noted that $\gamma$ phases were formed not only at the grain boundaries of $\alpha_{\mathrm{R}}$ and the interface between $\alpha_{\mathrm{R}}$ and $\alpha_{\mathrm{NR}}$ but also at subgrain boundaries inside $\alpha_{\mathrm{NR}}$ when the $\gamma$ fraction was more than at least $30 \%$, as reported in previous studies (Ogawa et al. 2010; Carozzo and Jacques 2007). The subgrain boundaries are usually low-angle boundaries (Humphreys and Hathery 1995) and have a lower energy (Read and Shockley 1950), compared to the recrystallization interfaces with highangle boundaries. These findings indicate that $\gamma$ phases nucleated preferentially at the grain boundaries of $\alpha_{\mathrm{R}}$ and at the interface between $\alpha_{\mathrm{R}}$ and $\alpha_{\mathrm{NR}}$ with higher levels of boundary energy at the early stage of annealing.

It has been reported that a large portion of $\alpha^{\prime}$ was observed at high-angle grain boundaries such as grain boundaries of $\alpha_{\mathrm{NR}}$ when the volume fraction of $\alpha^{\prime}$ was approximately $15 \%$ (Goodman 1984). These findings indicate that the $\gamma$ fraction is an important point for the nucleation site of $\gamma$, and the nucleation site of $\gamma$ is mainly a high-angle grain boundary when the $\gamma$ fraction is low. On the other hand, as mentioned above, pearlite colonies should be the nucleation sites for $\gamma$ when the microstructure before annealing consists of ferrite and pearlite (Huang et al. 2004; Speich et al. 1981). Therefore, it appears that the microstructure before annealing can also affect the nucleation site of $\gamma$. Furthermore, it has been demonstrated that the microstructure before annealing affects the recrystallization behavior of $\alpha$ during annealing in cold-rolled low-carbon steels (Yamaguchi et al. 2011). The influence of the microstructure before annealing on the competition phenomenon between recrystallization of $\alpha$ and formation of $\gamma$ during annealing is an important issue for further clarification.

\section{Conclusions}

We have investigated the recrystallization of $\alpha$ and the formation of $\gamma$ at the early stages of annealing in coldrolled low-carbon steels, and the following results were obtained.

(1) Recrystallization of $\alpha$ was able to proceed during intercritical annealing even if the $\gamma$ fraction was less than $10 \%$, although the grain size of $\alpha_{\mathrm{R}}$ and subgrains formed in $\alpha_{\mathrm{NR}}$ hardly changed. This result suggests that progress of $\alpha$ recrystallization at the early stages of annealing at the intercritical temperature mainly originates in continuous recrystallization.

(2) A large portion of $\gamma$ was formed at the grain boundaries of $\alpha_{\mathrm{R}}$ and at the interface between $\alpha_{\mathrm{R}}$ and $\alpha_{\mathrm{NR}}$ at the early stage of annealing, although cementite particles were homogeneously distributed.

(3) Solute $C$ generated by the dissolution of cementite diffused to high-angle grain boundaries, thereby causing the formation of $\gamma$ at the grain boundaries of $\alpha_{R}$ and the interface between $\alpha_{\mathrm{R}}$ and $\alpha_{\mathrm{NR}}$ at the early stages of annealing. 


\section{Competing interests}

The author declares that he has no competing interest.

\section{Acknowledgements}

This work was supported by a research grant from the SUZUKI Foundation, Japan.

Received: 3 June 2015 Accepted: 7 August 2015

Published online: 18 August 2015

\section{References}

Carozzo, VA, \& Jacques, PJ. (2007). Interactions between recrystallization and phase transformations during annealing of cold-rolled Nb-added TRIP-aided steels. Materials Science Forum, 539-543, 4649-4654.

Garcia, Cl, Cho, K, Gong, Y, Chen, TR, \& Deardo, AJ. (2005). Development of high strength, low-carbon, $\mathrm{Nb}$-bearing dual-phase steels for production on continuous galvanizing lines. Materials Science and Technology, 2, 77-86.

Goodman, SR. (1984). Metallurgy of high-strength cold-rolled steel sheets (pp. 239-252). ASM, Ohio: Conf. Proc. of Int. Conf. On Technology and Applications of HSLA steels.

Hashimoto, N, Yoshinaga, N, \& Senuma, T. (1998). Texture evolution of IF steel due to recrystallization. ISIJ International, 38, 617-624.

Hayami, S, Furukawa, T, Gondoh, H, \& Takachi, H. (1979). Formable HSLA and dual-phase steels (pp. 167-180). New York: AIME.

Hillert, M, Nilsson, K, \& Torndahl, L-E. (1971). Effect of alloying elements on the formation of austenite and dissolution of cementite. Journal of the Iron and Steel Institute of Japan, 209, 49-66.

Huang, J, Poole, WJ, \& Militzer, M. (2004). Austenite formation during intercritical annealing. Metallurgical and Materials Transactions A, 35A, 3363-3375.

Humphreys, FJ. (1997). A unified theory of recovery, recrystallization and grain growth, based on the stability and growth of cellular microstructures-I. The basic model. Acta Materialia, 45, 4231-4240.

Humphreys, J. (2004). Nucleation in recrystallization. Materials Science Forum 467-470, 107-116.

Humphreys, FJ, \& Hathery, M. (1995). Recrystallization and related annealing phenomena (p. 144). Oxford: Pergamon.

Jeong, WC, \& Kim, CH. (1985). Formation of austenite from a ferrite-pearlite microstructure during intercritical annealing. Journal of Materials Science, 20, 4392-4398.

Maruyama, N, Ogawa, T, \& Takahashi, M. (2007). Recrystallisation at intercritical annealing in low carbon steel. Materials Science Forum, 558-559, 247-252.

Mukunthan, K, \& Hawbolt, EB. (1996). Modeling recovery and recrystallization kinetics in cold-rolled Ti-Nb stabilized interstitial-free steel. Metallurgical and Materials Transactions A, 27, 3410-3423.

Nishitani, N, Hiramoto, T, Takemoto, Y, \& Senuma, T. (2011). Model for predicting recrystallization behavior of cold rolled extralow carbon steel sheets. Tetsu to Hagane, 97, 238-244.

Nishizawa, T. (1984). Grain growth in single- and dual-phase steels. Tetsu to Hagane, 70, 1984-1992.

Nonaka, T, Fujita, N, Taniguchi, Y, Tomokiyo, T, \& Goto, K. (2007). Development of ultra-high-strength steel sheets with excellent formabilities. Materia Japan, 46, 108-110.

Ogawa, T, Maruyama, N, Sugiura, N, \& Yoshinaga, N. (2010). Incomplete recrystallization and subsequent microstructural evolution during intercritical annealing in cold-rolled low carbon steels. ISIJ International, 50, 469-475.

Read, WT, \& Shockley, W. (1950). Dislocation models of crystal grain boundaries. Physics Review, 78, 275-289.

Speich, GR, \& Szirmae, A. (1969). Formation of austenite from ferrite and ferrite-carbide aggregates. Transactions of the Metallurgical Society of AIME, 245, 1063-1074.

Speich, GR, Demarest, VA, \& Miller, RL. (1981). Formation of austenite during intercritical annealing of dual phase steels. Metallurgical Transactions A, 12A, 1419-1428

Takayama, T, Wey, MY, \& Nishizawa, T. (1982). Grain growth in dual-phase steel. Tetsu to Hagane, 68, 122-129.

Takechi, H. (1994). Metallurgical Aspects on interstitial free sheet steel from industrial viewpoints. ISIJ International, 34, 1-8.

Toji, Y, Yamashita, T, Nakajima, K, Okuda, K, Matsuda, H, Hasegawa, K, \& Seto, K. (2011). Effect of Mn partitioning during intercritical annealing on following $\gamma \rightarrow a$ transformation and resultant mechanical properties of cold-rolled dua phase steels. ISIJ International, 51, 818-825.
Yamaguchi, Y, Okamoto, R, \& Fujita, N. (2011). Influence of microstructure change in hot strip on the recrystallization behavior in cold rolled steel sheets. CAMP-ISIJ, 24, 203

Yang, DZ, Brown, EL, Matlock, DK, \& Krauss, G. (1984). Ferrite recrystallization and austenite formation in cold-rolled intercritically annealed steel. Metallurgical Transactions A, 16A, 1385-1392.

Ye, W, Gall, RL, \& Saindrenan, G. (2002). A study of the recrystallization of an IF steel by kinetics models. Materials Science and Engineering, 332, 41-46.

\section{Submit your manuscript to a SpringerOpen ${ }^{\odot}$ journal and benefit from:}

- Convenient online submission

- Rigorous peer review

- Immediate publication on acceptance

- Open access: articles freely available online

- High visibility within the field

- Retaining the copyright to your article

Submit your next manuscript at $>$ springeropen.com 